\title{
Innovative Method in Digitizing a Web-based OSCE Evaluation System for Medical Students: A University Hospital Experience.
}

\section{Abdullah Yousef}

Department of Pediatrics, College of Medicine, Imam Abdulrahman Bin Faisal University, Dammam, Saudi Arabia.

\section{Bassam Awary}

Department of Pediatrics, College of Medicine, Imam Abdulrahman Bin Faisal University, Dammam, Saudi Arabia.

\section{Faisal AlQurashi ( $\nabla$ faisal.alqurashi@yahoo.com )}

Department of Pediatrics, College of Medicine, Imam Abdulrahman Bin Faisal University, Dammam, Saudi Arabia.

\section{Waleed Albuali}

Department of Pediatrics, College of Medicine, Imam Abdulrahman Bin Faisal University, Dammam, Saudi Arabia.

\section{Mohammad Al-Qahtani}

Department of Pediatrics, College of Medicine, Imam Abdulrahman Bin Faisal University, Dammam, Saudi Arabia.

\section{Syed Husain}

Vice Deanship for e-learning, College of Medicine, Imam Abdulrahman Bin Faisal University, Dammam, Saudi Arabia.

\section{Omair Sharif}

Vice Deanship for e-learning, College of Medicine, Imam Abdulrahman Bin Faisal University, Dammam, Saudi Arabia.

\section{Research Article}

Keywords: Clinical Education, Computers, Simulation, New Technology, Evaluation/Assessment of Clinical Performance, Interdisciplinary Medical Education, Testing/Assessment

Posted Date: January 23rd, 2021

DOI: https://doi.org/10.21203/rs.3.rs-143684/v1 
License: (c) (i) This work is licensed under a Creative Commons Attribution 4.0 International License. Read Full License

Version of Record: A version of this preprint was published at International Journal of General Medicine on February 3rd, 2022. See the published version at https://doi.org/10.2147/IJGM.S351052. 


\section{Abstract}

Background: The Objective Structured Clinical Examination (OSCE) is a standard academic assessment tool in the field of medical education. This study aimed to present an innovative method for digitizing a computerized web-based Objective Structured Clinical Examination (OSCE) evaluation system for medical students and explore its efficacy compared to the traditional paper-based system, through the analysis of a User Satisfaction Survey.

Method: A cross-sectional, questionnaire-based study involving a User Satisfaction Survey to test assessors' attitudes to and acceptance of the new Computerized Web-based OSCE Evaluation System (COES) was used. Fifth-year medical students in the College of Medicine, Imam Abdulrahman Bin Faisal University, Dammam, Saudi Arabia were assessed clinically through their 2019 end-of-year OSCE examination by 30 examiners in five different OSCE stations. The traditional paper-based stations were converted into an online electronic version using QuestionPro software. Answers were filled using smart tablets (iPads). QR codes were used for students' identification at each station to fully digitize the process and save time. After the completion of the exam, a User Satisfaction Survey was sent electronically to all examiners to evaluate their experiences with the new system.

Results: The response rate for the survey was $100 \%$ with an internal consistency of 0.83 . Almost all the examiners $(29,97 \%)$ were satisfied with the application of the new OSCE electronic system. Further, $72 \%$ of the examiners indicated that the new electronic system facilitated the evaluation of the students' skills, and $84 \%$ found using a smart device (iPad) was easier than using a paper form. All examiners expressed their preference for using the new electronic system in the future.

Conclusion: Users were satisfied with the utilization of the new customized COES. This concept of fully digitizing the OSCE assessment process shortened the time needed for both the analysis of results and providing students with feedback. Further observational studies are needed to assess examiners' behaviors when using this new methodology.

\section{Background}

The Objective Structured Clinical Examination (OSCE) is a standard academic assessment tool in the field of medical education. It is designed to test and evaluate practical and communicative skills among medical students. ${ }^{1}$ Some of its advantages include building examinee confidence and testing their clinical sense in different settings. Among its disadvantages are the significant time expenditure incurred and possible individual documentation errors.

In 1975, Haden et al. introduced OSCE as a method to evaluate medical students' skills. ${ }^{2}$ Since then, it has been used as a mode for assessing skills and clinical competence of almost all healthcare practitioners. ${ }^{3}$ It is a timed examination in which students move systematically through a set of stations that are pre-determined and evaluated by a qualified examiner, using well-structured marking criteria. ${ }^{4}$ 
Historically, the concept of the OSCE examination has been subjected to numerous modifications throughout the years to better suit specific academic purposes. ${ }^{5,6}$ In most well-known colleges of medicine worldwide, OSCE is the standard tool for the evaluation of competency, clinical skills, communication skills, psychomotor skills, cognitive knowledge, and attitude through oral examination, counseling, data interpretation, and history and physical examination stations. ${ }^{7-10}$

The extent of the traditional clinical exam focused on the patient's history and a demonstration of physical examination skills, with a minimal assessment of technical skills. The traditional clinical exam has been shown to be broadly unreliable and unjust in evaluating students' performance because of the wide range of variability concerning both the examiners and the actual selected patients. ${ }^{11}$ "The luck of the draw" in the selection of examiner and patient plays a significant negative role in the outcome when using the traditional method. ${ }^{12}$ Since the introduction of the concept of OSCE in 1975, researchers' findings reported it to be reliable, objective, and valid with the cost and requirement for human resources being its main disadvantages. ${ }^{7-12}$ In OSCE, all students are examined on preselected criteria determined by a team of faculty teachers. Assessment of similar clinical scenarios or tasks with scores to meet specific criteria are undertaken. The diversity of stations, performance outcomes, degree of difficulty of questions, and overall students' organization are some of the important parameters that can be used to analyze the teaching standards of the institution objectively. During the exam, students' performance is judged not by two or three examiners but by a team of examiners in-charge of the various stations of the examination. Furthermore, OSCE is time-efficient, examining more students in any given time over a broader range of subjects than the traditional clinical exam. ${ }^{13}$

Classically, paper-based methodology was the standard when executing OSCEs. However, several issues have been linked to this method, including uninterpretable handwriting, missing students' details, lost assessment sheets, individual manual calculation inaccuracy, data entry errors, and time consumption. Additionally, feedback and prospective input regarding students' performance are not usually shared with students due to time limitations. ${ }^{14}$ There are few published papers highlighting different practical approaches to overcome these shortfalls. Most of these efforts tackled the core deficits of the traditional paper-based OSCE assessment, including digital use of different software programs, ${ }^{14,15}$ use of computers and electronic handheld devices, ${ }^{16-19}$ and use of a web-based evaluation system. ${ }^{20}$

E-learning at the College of Medicine in Imam Abdulrahman Bin Faisal University is rapidly evolving to surpass international standards in electronic learning. To our knowledge, this is the first audit tackling the topic of OSCE assessment of students using a new electronic strategy involving the designing and implementing of online handheld digital OSCE assessment software. This study aims to present a new academic assessment tool using a customized Computerized Web-based OSCE Evaluation System (COES) for medical students and explore its efficacy in comparison to the traditional paper-based evaluation system, using a User Satisfaction Survey.

\section{Methods}


We selected a User Satisfaction Survey to explore the efficacy of the digitized OSCE system compared to the traditional paper-based system. As part of the Children's Health academic requirement, fifth-year medical students at the College of Medicine, Imam Abdulrahman Bin Faisal University, Dammam, Saudi Arabia, must be assessed clinically through an end-of-year OSCE examination following their Children's Health course. The e-learning unit at the College of Medicine decided to digitize the OSCE examination for all medical students to meet its strategic academic plans, and the Department of Pediatrics was chosen as a trial. Numerous meetings and brain storming sessions were held to gauge such requirements and how effectively/efficiently they could be conducted utilizing available resources, customized to the needs of the department.

QuestionPro is a web-based software for creating and distributing surveys. It consists of an interface for creating survey questions, tools for distributing surveys via email or website, and tools for analyzing and viewing the results. ${ }^{21}$ To fit our purpose, as an OSCE management solution, we created a full exam platform by utilizing survey features and went one step further by using QR codes. QuestionPro has been "globally recognized by multiple educational, business, research, and marketing institutes for over ten years." 21

Assessment documentation, stations selection, and scoring criteria were chosen, formulated, reviewed, and agreed on by the OSCE committee faculty members of the department. Subsequently, all information was handed to the e-learning support team to be uploaded to the newly generated assessment system using QuestionPro software. Prior to the OSCE date, OSCE assessors, circuit coordinators, and student invigilators were trained to use the electronic system, and technical support was available at the time of the OSCE assessments. Further, an introductory session was held to introduce the new electronic system to the students.

Regarding OSCE scoring, we provided assessors with 3-5 scoring options for each question of the assessment with which to rate each student's performance: Not Done, Inadequately Done, Partially Done, Adequately Done, and Well Done. We assigned different scoring weights to each question based on its difficultly, complexity, and number of variable answers for each question (Fig. 1).

This new COES, which was customized "in-house" at the e-learning unit of College of Medicine at Imam Abdulrahman Bin Faisal University, was used to store and analyze data electronically. Moreover, student feedback was sent to students electronically using the student email system.

This study was approved by the Institutional Review Board (IRB) of Imam Abdulrahman Bin Faisal University through an expedited review (IRB approval number IRB-2020-01-048). The datasets used and/or analyzed during this study are available from the corresponding author on reasonable request.

\section{OSCE layout for the students}

A total of 139 fifth-year medical students utilized the new electronic OSCE assessment system in December 2019. They were assessed by 30 examiners from the faculty board of the Department of 
Pediatrics using portable tablets (iPads) that were provided by the Deanship of e-learning. The OSCE comprised five separate stations. Students were divided into three parallel circuits (A, B, and C) operating simultaneously to accommodate numerous examinees. Each circuit comprised the same five stations in the same systematic order. A range of 12-14 students were assigned prior to the exam to four rotations per circuit. This distribution of students was meticulously generated using Excel Microsoft software and reviewed by three different members of the OSCE exam committee to eradicate any individual/technical errors. Each student completed a history taking and discussion, pediatric surgery case scenario, data interpretation, physical examination, and counseling station, each of which was eight minutes.

\section{The Computerized Web-based OSCE Evaluation System}

The duration of the station was determined by the required time for the student's assessment, for the student's QR code to be scanned, and a two-minute safety zone should any electronic issue arise. A QR color-coded ID card was given to each student before entering the exam to be scanned by each assessor using their iPads at the beginning of the station (Figs. $2 \& 3$ ).

The coded card showed the student's data (Name, University number) and was encrypted to match the assigned circuit, assessor, and rotation for each student. Once the assessor scanned the QR code on each student's ID card, an online designed page opened on the assessor's tablet showing the student's data, circuit, and rotation numbers for second step verification (Fig. 4). Subsequently, the assessor was asked to choose their assigned station number from the five stations shown on that page, which also showed the relevant assessors' names under each station. After selecting a station, the assessor graded the performance of the student within the given time frame (Fig. 5).

Once the time was up, the assessor submitted the form, and data were recorded in the system. After submission of the performance questionnaire, an automated text appeared containing the student data and a message confirming the submission of the questionnaire. Notably, the submission of performance forms was only allowed when all questionnaire items were completed to overcome missing data potential. Finally, the software can be used to download the raw data results in different formats (MS Excel, MS PowerPoint, Adobe PDF) during or after the completion of the exam. The serial number can be used to merge the data for each student in a single MS Excel file, and the sum and average formulas can be added manually through the MS Excel function "sort" (Fig. 6).

\section{Overall User Satisfaction Survey}

After the completion of the exam, we asked the assessors to complete an overall satisfaction survey of their experience with the new electronic system (COES). The survey was originally developed from a previous work following an extensive literature review in the field of electronic OSCE management. ${ }^{16,22} \mathrm{~A}$ 25-item-questionnaire was divided into three sections: the OSCE Software user evaluation (3 Items); usage of the electronic OSCE system and its training (10 Items); and the OSCE assessment process itself (12 Items). For the questions related to the usage of the electronic OSCE system and the assessment process itself (22 Items), they chose from the following: Strongly agree, Agree, Disagree/strongly disagree, or No judgment. For the OSCE software user evaluation (3 Items), the choices were as follows: 
Excellent, Good, Fair, or Poor. Additionally, three other questions were added for a better analysis of the process: Assessor's age, gender, and whether they possessed a tablet device at home. The assessors' answers were recorded and analyzed.

\section{Results}

Two-third of the assessors were male $(22,73.3 \%)$, and the majority were above the age of 40 years $(13$, $43.3 \%$ ), with six examiners (20\%) being above the age of 50 years, and the rest were between the age of 30 to 39 years. Most assessors have personal tablets at home $(23,76.6 \%)$, with no observed statistical significance compared to their age or gender. The overall average time for completing all the students' assessments was five minutes (out of a possible eight minutes).

\section{User Satisfaction Survey for Assessors}

All the assessors who received the survey electronically completed it with a response rate of $(n=30$, $100 \%$ ). The internal consistency (Cronbach's alpha) of the survey was 0.83 . In classical psychometric terms, internal consistency was preferred to best. ${ }^{23}$

All examiners had previous experience with assessing students using paper-based OSCE methodology. Answers that showed "No judgment" were excluded during the descriptive analysis since there was no preference regarding either agreement or disagreement and they were not considered significant when forming a conclusion for a satisfaction survey. Results of the satisfaction survey for assessors are displayed in Table 1. 
User Satisfaction Survey results $(\mathrm{n}=30)$

\section{Section A:}

Training for and usage of the Computerized Webbased OSCE Evaluation System (COES)
Strongly Agree agree
1. The training sessions prepared me sufficiently to use 20 the system

2. It was easy to access the computer system

3. The screen layout and instructions were clear

4. The computer system was easy to use

5. I felt confident using the computer system

6. Multiple-choice markings were easy to navigate

7. There was good technical support provided to help me with any problems

8. Using the system enabled me to complete my work as an examiner efficiently

9. It was easy to exit from the program

10. I would like to use the electronic system for future OSCES

\section{Section B:}

The OSCE assessment process

11. Using the computer system facilitated the assessment of the students' skill

12. The outlined steps of the skill were appropriate to the skill being assessed

13. Having to use a smart device during the assessment was easier than using a paper form

14. Absent students were easy to manage

15. Late arrival students were easy to manage

16. The grading options were appropriate

17. Being able to input comments on student's performance was useful

12

12

2

10

10

$\begin{array}{llll}21 & 9 & 0 & 0 \\ 23 & 7 & 0 & 0 \\ 23 & 7 & 0 & 0 \\ 22 & 8 & 0 & 0 \\ 18 & 9 & 0 & 3 \\ 26 & 4 & 0 & 0\end{array}$

21

12

21

Strongly Agree agree

15

7
9

7

1

0

0

strongly

disagree
No

judgment

$\begin{array}{ll}0 & 1\end{array}$

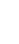

1

2

2

2

No

judgment

\section{strongly} disagree

\begin{tabular}{ll}
$\begin{array}{l}\text { Disagree } \\
\text { or }\end{array}$ & No \\
\hline $\begin{array}{l}\text { strongly } \\
\text { disagree }\end{array}$ & judgment \\
\hline
\end{tabular}

$\begin{array}{llll}9 & 9 & 7 & 5\end{array}$

18

0

0

5

10

4

4

8

2

18

26

3

19

19

0

1

12

5

3 


\section{Section A: \\ Training for and usage of the Computerized Web- based OSCE Evaluation System (COES)}

Strongly Agree

agree
Disagree
or

strongly disagree
No

judgment

18. I felt that I had to include a comment on students' 4 performance for each student

$\begin{array}{llll}4 & 7 & 12 & 7\end{array}$

19. I included a comment when I judged that a student

had not completed an element of the skill appropriately

20. Not being able to see the students overall score was good

21. Being able to give a global rating for each student was good

22. Not being able to see the score for each criterion was good

Section C:

Excellent Good Fair

Poor

Overall OSCE Software user acceptance

23. Grade your overall acceptance of the application of 20 the new electronic system

24. Grade your overall students' assessment using the 20 new electronic system

25. Overall level of satisfaction

21

8

1

0

Almost all the assessors (29, 97\%) were satisfied with the application of the new OSCE electronic system in assessing the medical students' performance. Most examiners (18/25, 72\%) indicated that the new electronic system facilitated the evaluation of the students' skills. Most examiners $(22 / 26,84 \%)$ found using a smart device (iPad) was easier than using a paper form; the remainder found the paper form easier $(4 / 26,16 \%)$. More than half of the examiners $(16 / 26,61.5 \%)$ felt that they had to include a comment on students' performance at the end of the assessment in the comments section. Over twothirds of the examiners answered the questions related to the usage of the COES (Section A) positively with few negligible exceptions. All examiners (28/28, 100\%) expressed their preference for using the new electronic system in the future.

\section{Discussion}

Overall, most of the assessors recorded good to excellent feedback on the User Satisfaction Survey. Our Cronbach's alpha value is much higher than that reported by another similar Irish study (0.83 vs. 0.14$).{ }^{16}$ This could be due to our larger number of examiners (30 vs. 18) or because of a social desirability bias issue in that study. More than $95 \%$ of the examiners were satisfied with implementing the new QR-coded COES in assessing the fifth-year medical students. Such observation supports the findings of Meskell et al., which showed that their application of an online OSCE system was satisfactory. ${ }^{16}$ Furthermore, all our 
examiners agreed to use the same methodology with some slight modifications in the future. Suggested interventions included a better internet connection and adding a question assessing the student's Global Rating Score. No examiner was forced to deal with network connection problems by themselves as we ensured the continuous presence and support of our technical team. Additionally, Wi-Fi connectivity was tested prior to the application of the online assessments. Multiple factors supported and augmented the new experience. These include the following: Preparatory training sessions; the system's easy accessibility; clarity of the system's layout and instructions; easy navigation of the multiple-choice scorings; and the availability of technical support. The newly tailored functionalities provided by the new electronic OSCE assessment system using QuestionPro enabled the examiners to easily evaluate, track, intervene, and comment on each student's performance. To our knowledge, this work represents the first trial of a fully integrated QR-coded COES worldwide. A relatively recent Irish study by Meskell et al. tracked a cohort of first-year nursing students over two consecutive years $(n=203)$ using a "built-in" online OSCE management information system. It found that electronic software facilitated the analysis of overall results, thereby offering considerable time savings. ${ }^{16}$ Similarly, the application of our novel electronic system significantly shortened the time needed for the analysis of the results, allowing more time for data interpretation for better curriculum development and clinical teaching improvements. As the survey was adopted from a previous work, ${ }^{16}$ we decided to limit our modifications to some of its items for comparison. For more clarification, items such as "Absent students were easy to manage" or "Late arrival students were easy to manage" could not be interpreted adequately as absentees and late arrivals were dealt by the OSCE coordinators rather than the examiners themselves. Other survey items that dealt with the OSCE assessment process were "I felt that I had to include a comment on student performance for each student" or "I included a comment when I judged that a student had not completed an element of the skill appropriately." These showed significant variability between the assessors; therefore, they were difficult to interpret as well. However, to better suit the newly applied electronic system, we tried to overcome all the obstacles that may affect students' assessment by anticipation. As the traditional paper-based method for OSCE assessment was easy to follow and allowed the examiners to add their comments on each student's performance, the new COES guaranteed this right by adding an optional "Comment section" functionality at the end of each student encounter. The use of QR-coding in OSCE assessment was not previously reported in the literature. A qualified e-learning team is required to deliver high-end technology for numerous simultaneous encounters. Around 695 QR-coded interactions between the students and their examiners were recorded during our electronic OSCE assessment. This requires good preparatory technical support as well as excellent cooperation between academic and technical teams. Our new concept of fully digitizing the OSCE assessment process shortened the time needed for both the analysis of results and providing students with feedback. According to our preliminary exploration, we estimate that the new approach saved us more than 48 hours of data entry, data analysis, and final student grading.

This study had its limitations. First, the relatively small number of stations $(n=5)$ might play a significant role in the feasibility of applying such a fully electronic OSCE assessment system on a larger scale. However, we believe that having more than 650 overall student encounters with the new system without 
any major shortcomings ensured its safety and applicability. Second, the small number of examiners $(\mathrm{n}=$ 30) could carry its negative impact on the User Satisfaction Survey results, but the number of our examiners is much bigger than other relevant studies in the same field with better consistency values. Finally, the possibility of assessors becoming distracted by using the new online OSCE tool is logically high. However, we did not perceive any negative effects in this regard, apart from what has been mentioned in the User Satisfaction Survey results. Additional observational studies on examiners' behaviors during the online OSCE methodology are required.

\section{Conclusions}

In conclusion, our COES for medical students showed promising results for the potential to transition from traditional paper-based OSCE assessment into a fully digitized and online system. Users of this novel digital online assessment tool demonstrated a high level of satisfaction. Preparatory training sessions, the system's easy accessibility, clarity of the system's layout and instructions, easy navigation of the multiple-choice scorings, as well as the availability and readiness of technical support are integral to the success of this new approach. Further observational studies are needed to assess examiners' behaviors when using this new methodology.

\section{Abbreviations}

OSCE: Objective Structured Clinical Examination

COES: Computerized Web-based OSCE Evaluation System

QR codes: Quick Response codes

\section{Declarations}

\section{Ethical approval and consent to participate:}

This study was approved by the Institutional Review Board (IRB) of Imam Abdulrahman Bin Faisal University through an expedited review (IRB approval number IRB-2020-01-048) which also waived the need for informed consent. Authors of the study confirm that all methods were carried out in accordance with relevant guidelines and regulations.

\section{Consent for publication:}

Not applicable.

\section{Availability of data and materials:}


The datasets used and/or analyzed during this study are available from the corresponding author on reasonable request.

\section{Competing interests:}

The authors report no competing interests in this work.

\section{Funding:}

None.

\section{Authors' contributions:}

All the study authors contributed equally to this work. AAY and BHA were responsible for the proposal writing and literature review process. FOQ was responsible for distributing, collecting, and analyzing the Users Satisfaction Survey. FOQ, MHQ and WHA were responsible for the manuscript writing. Finally, SIH and OS were responsible for writing the technical part of the manuscript dealing with the used software and designing the study figures. All the previous Co-authors, including the principle author, did approve the final manuscript in its current submitted version.

\section{Acknowledgments:}

The authors wish to thank the University \& College of Medicine administration for their supervision of the process, and the Deanship of E-learning, Imam Abdulrahman Bin Faisal University, and the e-learning unit at the College of Medicine for their continuous technical support. Further, the authors express their gratitude to all the staff members of the Department of Pediatrics and the fifth-year medical students for their cooperation and thoughtfulness.

\section{References}

1. Patricio MF, Juliao M, Fareleira F, Carneiro AV. Is the OSCE a feasible tool to assess competencies in undergraduate medical education? Med Teach. 2013;35(6):503-514.

2. Harden RM, Stevenson M, Downie WW, Wilson GM. Assessment of clinical competence using objective structured examination. Br Med J. 1975;1(5955):447-451.

3. Oranye NO, Ahmad C, Ahmad N, Bakar RA. Assessing nursing clinical skills competence through objective structured clinical examination (OSCE) for open distance learning students in Open University Malaysia. Contemp Nurse. 2012;41(2):233-241. 
4. Pugh D, Touchie C, Wood TJ, Humphrey-Murto S. Progress testing: is there a role for the OSCE? Med Educ. 2014;48(6):623-631.

5. Hodges B. OSCE! Variations on a theme by Harden. Med Educ. 2003;37(12):1134-1140.

6. Stillman PL, Wang Y, Ouyang Q, Zhang S, Yang Y, Sawyer WD. Teaching and assessing clinical skills: a competency-based programme in China. Med Educ. 1997;31(1):33-40.

7. Novack DH, Volk G, Drossman DA, Lipkin M Jr. Medical interviewing and interpersonal skills teaching in US medical schools. Progress, problems, and promise. JAMA. 1993;269(16):2101-2105.

8. Jain SS, DeLisa JA, Eyles MY, Nadler S, Kirshblum S, Smith A. Further experience in development of an objective structured clinical examination for physical medicine and rehabilitation residents. Am J Phys Med Rehabil. 1998;77(4):306-310.

9. Baid $\mathrm{H}$. The objective structured clinical examination within intensive care nursing education. Nurs Crit Care. 2011;16(2):99-105.

10. Barry M, Noonan M, Bradshaw C, Murphy-Tighe S. An exploration of student midwives' experiences of the Objective Structured Clinical Examination assessment process. Nurse Educ Today. 2012;32(6):690-694.

11. Barman A. Critiques on the Objective Structured Clinical Examination. Ann Acad Med Singapore. 2005;34(8):478-482.

12. Zayyan M. Objective structured clinical examination: the assessment of choice. Oman Med J. 2011;26(4):219-222.

13. Hamann C, Volkan K, Fishman MB, Silvestri RC, Simon SR, Fletcher SW. How well do second-year students learn physical diagnosis? Observational study of an objective structured clinical examination (OSCE). BMC Med Educ. 2002;2(1):1186-1188.

14. Treadwell I. The usability of personal digital assistants (PDAs) for assessment of practical performance. Med Educ. 2006;40(9):855-861.

15. Segall N, Doolen TL, Porter JD. A usability comparison of PDA-based quizzes and paper-and-pencil quizzes. Comput Educ. 2005;45(4):417-432.

16. Meskell P, Burke E, Kropmans TJ, Byrne E, Setyonugroho W, Kennedy KM. Back to the future: An online OSCE Management Information System for nursing OSCEs. Nurse Educ Today. 2015;35(11):1091-1096.

17. Judd T, Ryan A, Flynn E, McColl G. If at first you don't succeed ... adoption of iPad marking for highstakes assessments. Perspect Med Educ. 2017;6(5):356-361.

18. Dearnley C, Haigh J, Fairhall J. Using mobile technologies for assessment and learning in practice settings: A case study. Nurse Educ Pract. 2008;8(3):197-204.

19. Schmidts MB. OSCE logistics-handheld computers replace checklists and provide automated feedback: Objective structured clinical examination. Med Educ. 2000;34(11):957-958.

20. Nackman GB, Griggs M, Galt J. Implementation of a novel web-based objective structured clinical evaluation. Surgery. 2006;140(2):206-211. 
21. How it works. https://www.questionpro.com/home/howltWorks.html. Accessed September 14, 2020.

22. Olsen, K. An examination of questionnaire evaluation by expert reviewers. Field Methods. 2010;22(4):295-318.

23. Cortina, J. M. What is coefficient alpha? An examination of theory and applications. J Appl Psychol. 1993;78(1):98.

\section{Figures}

\section{Logic}

Question: 3. Inspection: Symmetry \& Shape (Obvious lumps, swellings or distension) Surgical or other scars, pigmentation Umbilicus Visible peristalsis/ veins

Scoring

$\checkmark 8$

Answer options

Score

Not Done

0

Inadequately Done/ Cursory

Partially Done Correctly

Adequately Done

Well Done

Allow Customized Scaling

Show Weights on Report

Branching On Score

IF

Total Score

- is between 0

And

Jump to

- Select -

- $\oplus$

Default Branching:

No Branching

- If no branching options are selected, default branching will be executed.

Store section score in:

- Select -

Compute score if:

\section{Figure 1}

Software Question Logic page 


\section{Flowchart for OSCE Online Exam Using QuestionPro}

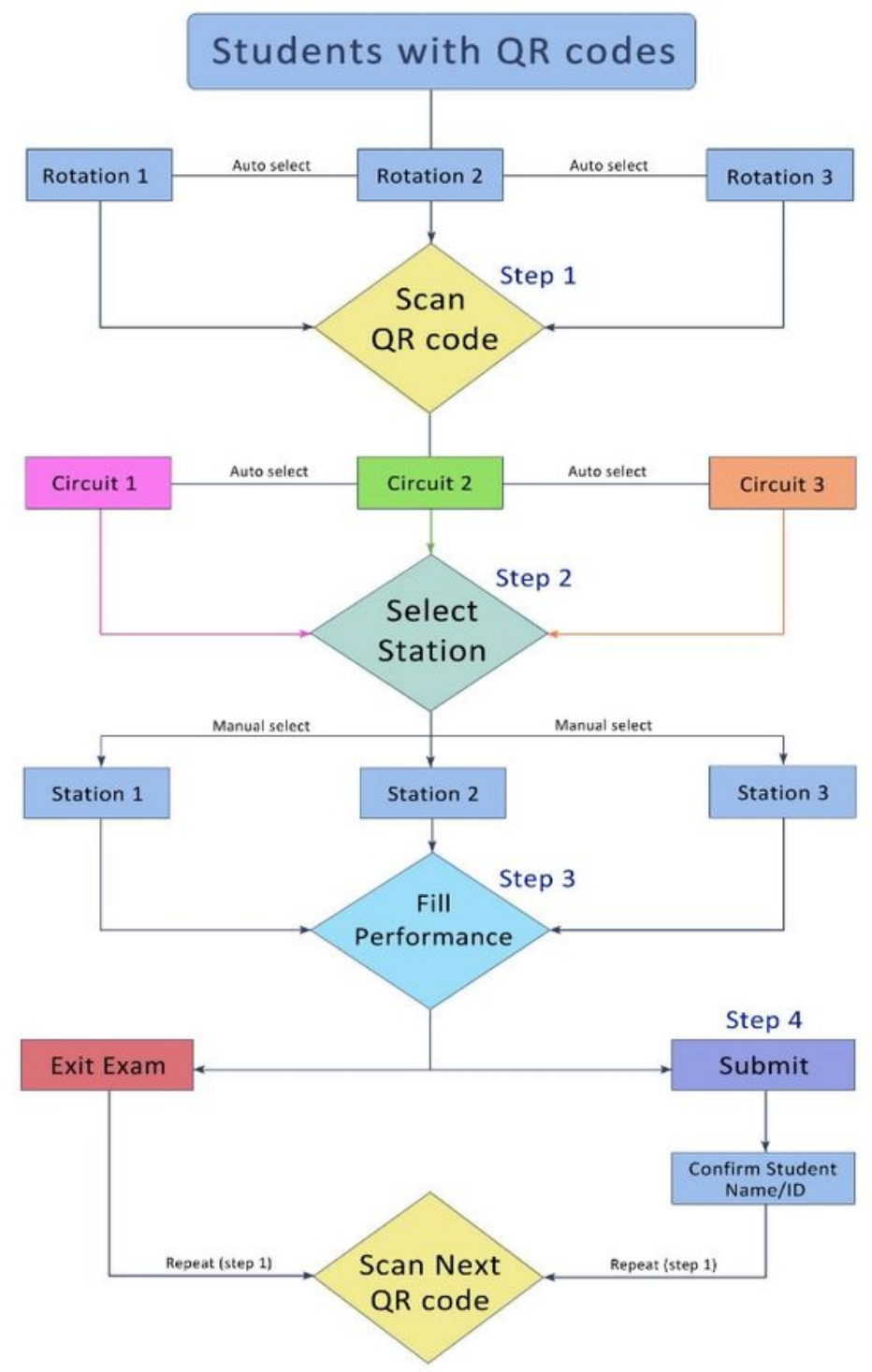

\section{Figure 2}

Flowchart for OSCE Exam using QuestionPro 


\section{Flowchart for OSCE Exam Using Other Online Solutions}

\section{Examinars with separate Login details}

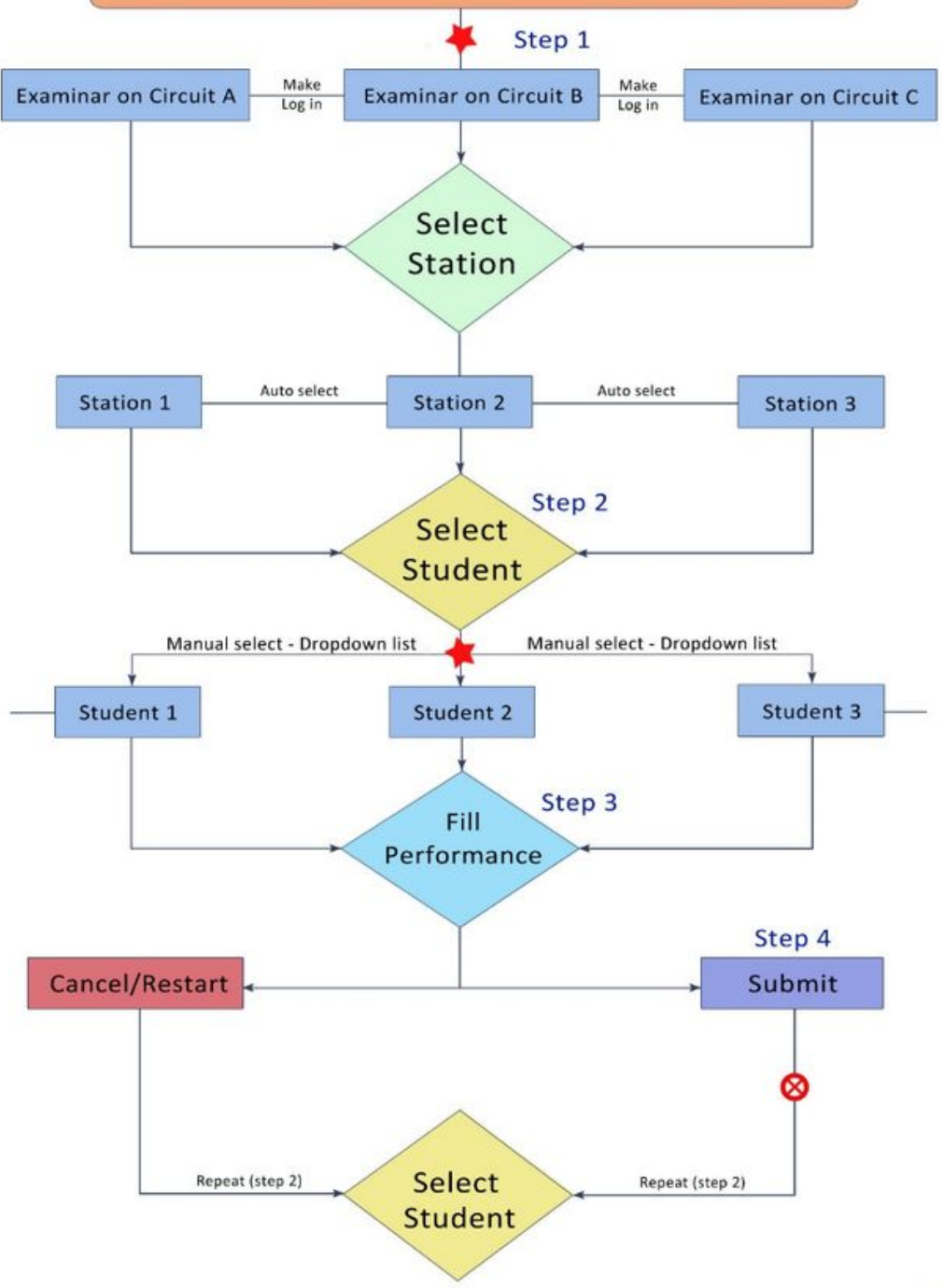

Probability of Human Errors

No cross check students details

\section{Figure 3}

Difference between QuestionPro and other online OSCE software 


\section{جامعة الإماه عبدالرحمن بن فيحل}

IMAM ABDULRAHMAN BIN FAISAL UNIVERSITY

Children Health OSCE (Year 5)

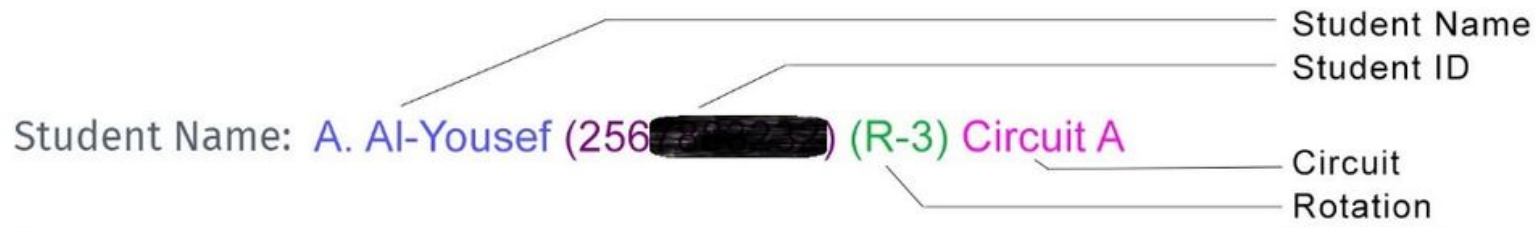

Please choose Station:

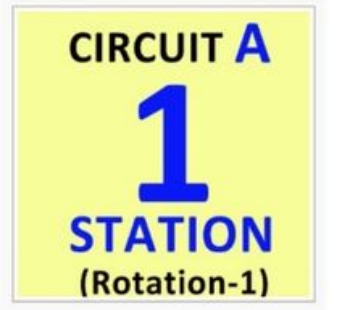

Dr. Hussah Al-Buainain

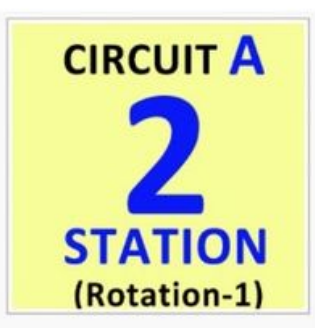

Dr. Hawazen Shash

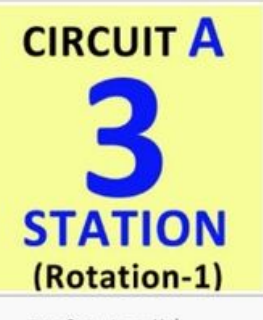

Prof. A. Lardhi

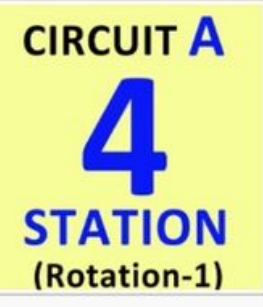

Prof. K. Al-Umran
CIRCUIT A

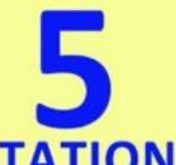

STATION

(Rotation-1)

Dr. K. Kamaleddin

\section{Select}

Powered by QuestionPro

\section{Figure 4}

User Interface Introduction page 
Station 5 (communication skills)

TIMER

$04: 50$

MINUTES SECONDS

Questions marked with a * are required

Student Name: A. Al-Yousef (256 (R-3) Circuit A

*1) Greets the patient and introduces self (full name, medical student, year level)

Not Done

Partially Done

Well Done

*2) Listens to the parents concerns

Not Done

Partially Done

Well Done

Comments

\section{Submit}

Figure 5

An example of the OSCE assessment page (Questionnaire sheet) 


\begin{tabular}{|c|c|c|c|c|c|c|c|c|c|c|}
\hline Srno & Students Names & Student ID & Unique ID & Station 1 & Station 2 & Station 3 & Station 4 & Station 5 & Total & $\begin{array}{c}\text { Final } \\
\text { Grades }\end{array}$ \\
\hline$\underline{1}$ & En & & $\mathrm{A} 1-\mathrm{F} 1$ & 90 & 91 & 89 & 79 & 98 & 447 & 89.4 \\
\hline$\underline{2}$ & 5 & & $\mathrm{~A} 1-\mathrm{F} 2$ & 90 & 70 & 47 & 59 & 90 & 356 & 71.2 \\
\hline$\underline{3}$ & 5 & & A1-F3 & 90 & 67 & 62 & 100 & 96 & 415 & 83 \\
\hline$\underline{4}$ & Disis & 5 & A1-F4 & 87 & 74 & 69 & 76 & 92 & 398 & 79.6 \\
\hline$\underline{5}$ & 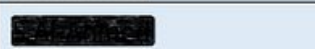 & 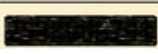 & A1-F5 & 90 & 56 & 64 & 44 & 96 & 350 & 70 \\
\hline
\end{tabular}

\section{Figure 6}

Collective students' results for all stations in a single MS Excel file. 